University of Nebraska - Lincoln

DigitalCommons@University of Nebraska - Lincoln

\title{
Reductions in grassland species evenness increase dicot seedling invasion and spittle bug infestation
}

\author{
Brian J. Wilsey \\ lowa State University \\ H. Wayne Polley \\ USDA-ARS Grassland, Soil and Water Research Laboratory, wayne.polley@ars.usda.gov
}

Follow this and additional works at: https://digitalcommons.unl.edu/usdaarsfacpub

Part of the Agricultural Science Commons

Wilsey, Brian J. and Polley, H. Wayne, "Reductions in grassland species evenness increase dicot seedling invasion and spittle bug infestation" (2002). Publications from USDA-ARS / UNL Faculty. 426.

https://digitalcommons.unl.edu/usdaarsfacpub/426

This Article is brought to you for free and open access by the U.S. Department of Agriculture: Agricultural Research Service, Lincoln, Nebraska at DigitalCommons@University of Nebraska - Lincoln. It has been accepted for inclusion in Publications from USDA-ARS / UNL Faculty by an authorized administrator of DigitalCommons@University of Nebraska - Lincoln. 


\section{REPORT}

\section{Reductions in grassland species evenness increase dicot seedling invasion and spittle bug infestation}

Brian J. Wilsey ${ }^{1}$ and H. Wayne Polley $^{2}$

${ }^{1}$ Department of Botany, 353

Bessey Hall, lowa State

University, Ames, IA 50011, USA.

${ }^{2}$ USDA-ARS, Grassland, Soil and

Water Research Laboratory,

Temple, TX 76502, USA.

*Correspondence:

Fax: 515-294-1337.

Tel.: 515-294-0232.

E-mail: bwilsey@iastate.edu

\begin{abstract}
Previous experiments that tested whether diverse plant communities have lower invasibility have all varied species richness. We experimentally varied evenness of four grassland species (three grasses and one forb) by planting a field experiment in Texas, and monitored the number of unplanted dicot and monocot species that invaded plots for two growing seasons. By varying evenness, we eliminated any sampling effect in our diversity treatment, because all plots contained the same plant species. Experimentally reducing evenness led to a greater number of dicot invaders, which emerged in plots throughout the growing season, but had less of an effect on monocot invaders, which emerged in flushes when experimental plants were semi-dormant. Frequency of Solidago canadensis (altissima) stems with spittle bugs significantly increased with reductions in evenness during the first year, apparently because the greater number of Solidago stems in high evenness plots diluted the spittle-bug effect. These results support the view that higher diversity plant communities are more resistant to dicot invaders and insect herbivores.
\end{abstract}

Ecology Letters (2002) 5: 676-684

\section{INTRODUCTION}

Changes in land use, habitat fragmentation, and in some cases, the increased dominance of introduced plants can reduce plant diversity in many ecosystems (reviewed by Chapin et al. 1997; Wilcove et al. 1998). Whether rates and stability of ecosystem processes are affected by reductions in diversity has recently re-emerged as an important and controversial topic of study. One important component of ecosystem stability is the ability to prevent outside species from invading, either from the same or different trophic levels. This stability component is usually hypothesized to be higher in communities that have high species diversity than in low-diversity communities (Elton 1958), and some recent experimental studies have supported this hypothesis. Knops et al. (1999), Naeem et al. (2000), Prieur-Richard et al. (2000), and Kennedy et al. (2002) found that species-rich experimental communities were more resistant to plant invaders than were species-poor communities. Lyons \& Schwartz (2001) found that invasion by Lolium multiflorum increased when the species richness of an intact community was experimentally reduced. The explanation most often used to explain these results is that species-rich communities utilize a greater proportion of available resources so that fewer resources are available to invading species (MacArthur 1972). In support of this, Tilman et al. (1996) found that nitrate availability was much higher in species-poor than species-rich communities in Minnesota. Moreover, fertilization often increases the number of plants that invade plant communities (e.g. Huenneke et al. 1990; Burke \& Grime 1996).

However, not all studies have found a negative relationship between plant diversity and plant invasion success, and the mechanistic explanation for a negative diversityinvasion relationship has been contested (Wardle 2001). First, there is often a strong and significantly positive relationship between the size of the species pool and the number of species that invade and establish in a site (Smith \& Knapp 1999; Stohlgren et al. 1999; Levine 2000; Lord \& Lee 2001). This usually leads to positive correlations between the number of native and exotic species in an area (Smith \& Knapp 1999; Stohlgren et al. 1999). Levine (2000) found that invasion success can be increased by increasing the size of the species pool but at the same time, can be depressed at the patch scale by high species richness. He argued that the species pool and patch diversity effects counteracted each other and acted on different scales, i.e. large scale factors that covary with diversity can overwhelm small scale processes and make the most species rich communities more invasible. Second, Wardle (2001) argued that negative relationships between invasion success and species richness often result because of differences in species composition between species rich and poor communities. He argued that species rich communities are less 
invaded because they are more likely to include aggressive plant species that fully exploit resources (i.e. the sampling effect). Thus, he argued that invasion success should be a function of species identities in the community, but not of species richness. Variation in recruitment has been found to depend on species composition of the community (Smith \& Knapp 1999; Levine 2000; Prieur-Richard et al. 2000; Lord \& Lee 2001) and disturbance history, which probably affect seedling establishment by indirectly changing resource availability (Levine \& D'Antonio 1999; Davis et al. 2000; B.J. Wilsey \& H.W. Polley, unpublished data). Davis et al. (2000) argued that it is fluctuations in resources that enhance species invasion, and that these pulses are usually unrelated to the species richness of the community.

Diversity has two components: species (or functional group) richness, or the number of species in a given area, and species evenness, or how well distributed abundance or biomass is among species (or functional groups) within a community. Varying evenness in experiments has seldom been done (Wilsey \& Potvin 2000; H.W. Polley et al., unpublished data), even though it explains a larger proportion of the variance $(53 \%)$ in diversity $\left(\mathrm{H}^{\prime}\right)$ of plant communities than does species richness $(6 \%)$ (Stirling \& Wilsey 2001). In an observational study of intact communities, Robinson et al. (1995) found that invasion success did not depend on species richness but was a function of the level of dominance exerted by a grass species, i.e. invasion success increased with species evenness.

In this study, we measured plant and insect invasion rates in plots in which we varied diversity by varying species evenness. We monitored the numbers of both dicot and monocot seedlings, a single sown plant species, Monarda citriodora, and a single sap-sucking insect species. By varying evenness and keeping species composition and density constant, a clear test of diversity effects can be made without confounding diversity and species identity, because all species are found in all plots (i.e. there is no sampling effect, Aarssen 1997; Huston 1997; Tilman et al. 1997; Doak et al. 1998; Wardle 2001). Experimentally varying species evenness has been found to affect primary productivity in some instances (Wilsey \& Potvin 2000) but not others (H.W. Polley et al., unpublished data). Nijs \& Roy (2000) predicted from a modelling exercise that communities with high evenness should utilize a greater proportion of available nutrients, if species are functionally different from one another. If fewer resources are available to invaders in communities with high evenness, these communities should have fewer plant invaders as a result.

Plants in diverse communities are predicted to have a lower herbivore load than are plants in low diversity communities according to the Resource Concentration Hypothesis of Root (1973). He predicted that pure stands of host plants would support fewer insect species, but that individuals would become much more abundant because of lowered predation, parasitism and/or competition rates compared to plants in diverse communities (also see Bach 1980 and Howe \& Westley 1988). In our experimental plots, one species (goldenrod, Solidago canadensis) was infested with spittle bugs during the first year of the study. Spittle bugs, which are xylem feeding insects, were found to have an important impact on Solidago in New York old fields (Root \& Cappuccino 1992; Meyer 1993; Carson \& Root 1999), and Knops et al. (1999) found that insect infestation rates were higher in plots with low species richness. Thus, we used the natural spittle bug infestation of our plots to test the hypothesis that invasion by species in higher trophic levels are affected by changes in plant species diversity (in this case, evenness).

\section{METHODS}

The experiment was conducted on lands at the Grassland, Soil and Water Research Laboratory (USDA-ARS) near Temple, TX during the 1999 and 2000 growing seasons. Rainfall, which averages $864 \mathrm{~mm}_{\text {year }}{ }^{-1}$, is bimodal, with a large peak during spring months and a smaller peak during autumn. Summers and winters are relatively dry. Prior to the experiment, the grassland was a hay field of naturalized species that dominate many grasslands of Texas, King ranch bluestem (Bothriochloa ischaemum) and bermuda grass (Cynodon dactylon). Plots were cleared of vegetation with herbicide several weeks before planting in spring 1999.

Plots were established by planting small transplants of three grasses and a forb (goldenrod, Solidago canadensis [sensu Solidago altissima]) into $85 \times 50 \mathrm{~cm}$ plots. All grasses are bunch grasses and include the native species meadow dropseed (Sporobolus asper) and silver bluestem (Botbriochloa laguroides) and Botbriochloa ischaemum. Plant species were randomly selected from a larger species pool present in adjacent grasslands that had not been grazed for 2-6 years (B.J. Wilsey \& H.W. Polley, unpublished data). Planting densities and the proportion of forbs to grass was based on data taken from nearby grasslands (unpublished data). Four species per plot were used, which is fairly low compared to many other studies. However, we used four species to be comparable to the 3.14 species per plot that was found in $50 \times 50 \mathrm{~cm}$ plots (range $1-5, n=21$ ) in the reference grasslands during late summer. Plants were transplanted from a nearby grassland into plots at a constant density of 32 plants. Grasses were trimmed from larger bunches into plants that were approximately the same size as the Solidago rhizomes; in this way we were able to equalize initial biomass among plots. Most transplants survived the initial planting; those that did not were replaced with similar sized transplants. Transplants were planted between 17 March and 1 April 1999. Plots were watered initially to facilitate establishment. 
The planting design was a $4 \times 4$ factorial design with 4 levels of evenness and with each of the 4 different species as the dominant. Eight individuals of each of the four species were planted into each 'high evenness' plot $(4 \times 8=32$ plants plot $\left.{ }^{-1}\right)$. Remaining evenness treatments were achieved by increasing the ratio of the dominant species to $14: 6: 6: 6$ (medium-high) to $20: 4: 4: 4$ (mediumlow) and $26: 2: 2: 2$ (low). Each of the 16 treatments was replicated 3 times for a total of 48 plots. Thus, the 16 groups represent grassland plots of differing levels of dominance by various species, in a manner analogous to realistic changes in evenness in natural grasslands. All 'high evenness' plots $(n=16)$ had the same relative abundances of each species and differed only in the location of the dominant species. These locations where maintained in low evenness plots.

In each plot, light capture by the canopy was estimated by comparing light levels (PPFD) above the canopy to four measurements at the soil surface in each plot during mid-day on a cloudless day in May 2000 (measured with a $50-\mathrm{cm}$ long Decagon ceptometer held diagonally). The proportion of light captured by the canopy was used to test whether high evenness canopies captured a larger proportion of available light than did lower evenness canopies. Percentage soil water content was measured with 3-4 time domain reflectometry (TDR) probes $(15 \mathrm{~cm}$ deep) in each plot.

Plots were weeded of invading plants monthly, or whenever necessary (i.e. less frequently outside actively growing periods). These plants were counted to determine effects of treatments on weed seedling emergence. Thus, plant 'invaders', in this case, were mostly individuals that invaded the community from the seed bank as well as some plants that germinated from seeds that blew into plots from surrounding vegetation. Seedling emergence is only the first step towards establishment, but seedlings were removed early in their development to prevent competitive effects on experimental transplants. During the second year of the experiment (2000), a common annual forb (Monarda citriodora) was seeded into one half of each plot at a rate of $4.5 \mathrm{~g}$ seeds $\mathrm{m}^{-2}$. The number of seedlings that emerged was quantified for each plot, and then seedlings were removed. Thus, seedling emergence rates were based on all species in the seed bank as well as on a controlled number of seeds of Monarda citriodora.

Invading seedlings were counted in all plots before the experiment began to verify that there were no initial differences in the seed bank among treatments and then (after transplants were planted) on 30 July 1999, and on 13 March, 18 May, 15 June 15, and 26 October 2000. Grass seedlings, which were more ephemeral than dicots, were counted on 30 July 1999 and on 18 May and 26 October 2000. Seedlings of Monarda were counted on 18 May, 15 June, 29 June, and 17 November 2000.
During the first growing season, spittle bugs (Clastoptera xanthocephala), common sap-sucking insects, infested Solidago. The proportion of stems that were infested was used as a measure of infestation rate. A stem was considered to be infested if it contained at least one spittle mass. During the second growing season (2000), there were very few infested stems, so data will be presented from year 1 only (1999).

By the end of the first growing season, a plant census revealed that the relative abundance of Solidago had increased in all plots, whereas the relative abundance of other species remained almost constant. For this reason, data were analysed with both ANOVA on the planted, categorical levels of evenness and with an ANOVA that used actual evenness levels (derived from an end-of-season census) as a regression variable. In our design, the importance of dominant species effects are tested with the species main effect, the importance of evenness with the evenness main effect, and whether species evenness effects are a function of which species dominated with the speciesevenness interaction.

\section{RESULTS}

\section{Invasive seedling counts}

Our analysis of the seed bank, conducted before the study began by counting the number of emerging seedlings, revealed no differences in the number of emerging dicots or monocots between plots assigned subsequently to evenness or species identity treatments (two-way ANOvA, $0.27<P<0.73$ ). Thus, any subsequent differences among treatments apparently were not because of pre-experiment differences in propogule supply.

There were significant effects of species evenness on dicot abundance, during the second growing season (Table 1 and Fig. 1). By March 2000, the number of dicot invaders per plot significantly declined with planted species evenness (Fig. 1) (even $P<0.02$, linear contrast: $F=9.3$, $P=0.005)$. These relationships remained significant during May (even $P<0.10$, linear contrast: $F=6.1, P=0.02$ ), and increased in strength during June (even $P<0.001$, linear contrast: $F=23.5, P<0.001$ ), and October 2000 (even $P<0.001$, linear contrast: $F=14.2, P<0.001)$. There were no significant (main effect) differences among species identity groups, i.e. the number of dicot invaders did not vary depending on which species dominated the plot (Table 1). There was also no interaction between species identity and evenness, which indicates that evenness effects on dicot seedling numbers were independent of the identity of the dominant species. Common invading species included the dicots Chamaesyce prostrata (Euphorbiaceae), Ambrosia psilostachya (Asteraceae), Draeba cuneifolia (Brassicacea), Oxalis spp. (Oxalidaceae), Croton sp. (Euphorbiaceae), 
Table 1 Results from ANOvAs of invading forb and grass seedlings, and seeded Monarda citriodora as a function of the dominant species identity (S), and planted and actual (sampled) species evenness (E)

\begin{tabular}{|c|c|c|c|c|c|}
\hline Source & d.f. & $\begin{array}{l}\text { Forb } \\
F(P)\end{array}$ & $\begin{array}{l}\text { Grass } \\
F(P)\end{array}$ & $\begin{array}{l}\text { Monarda } \\
F(P)\end{array}$ & $\begin{array}{l}\text { Frequency } \\
\text { of spittle } \\
\text { bugs } F(P)\end{array}$ \\
\hline \multicolumn{6}{|l|}{ Planted } \\
\hline Species & 3 & $0.4(0.78)$ & $0.3(0.86)$ & $1.1(0.35)$ & $3.5(0.03)$ \\
\hline Evenness & 3 & $13.1(<0.001)$ & $2.4(0.13)$ & $0.2(0.13)$ & $4.1(0.01)$ \\
\hline linear contrast & 1 & $15.6(<0.001)$ & $1.8(0.19)$ & $0.5(0.48)$ & $11.8(0.002)$ \\
\hline $\mathrm{S} \times \mathrm{E}$ & 9 & $0.3(0.80)$ & $0.5(0.72)$ & $0.5(0.88)$ & $1.5(0.20)$ \\
\hline Time $(\mathrm{T})$ & 4 & $14.5(<0.001)$ & $3.8(0.03)$ & & \\
\hline $\mathrm{T} \times \mathrm{S}$ & 12 & $1.1(0.34)$ & $0.7(0.63)$ & & \\
\hline $\mathrm{T} \times \mathrm{E}$ & 4 & $5.5(<0.001)$ & $1.4(0.25)$ & & \\
\hline $\mathrm{T} \times \mathrm{S} \times \mathrm{E}$ & 12 & $1.1(0.36)$ & $1.0(0.46)$ & & \\
\hline \multicolumn{6}{|l|}{ Actual } \\
\hline Species & 3 & $0.3(0.80)$ & $1.4(0.27)$ & $1.4(0.26)$ & \\
\hline Evenness & 1 & $5.4(0.004)$ & $0.6(0.62)$ & $0.6(0.46)$ & \\
\hline $\mathrm{S} \times \mathrm{E}$ & 3 & $0.1(0.99)$ & $1.0(0.45)$ & $1.6(0.20)$ & \\
\hline Time & 4 & $79.9(<0.001)$ & $26.2(<0.001)$ & & \\
\hline $\mathrm{T} \times \mathrm{S}$ & 12 & $0.3(0.99)$ & $1.2(0.33)$ & & \\
\hline $\mathrm{T} \times \mathrm{E}$ & 4 & $2.0(0.03)$ & $1.6(0.16)$ & & \\
\hline $\mathrm{T} \times \mathrm{S} \times \mathrm{E}$ & 12 & $1.1(0.34)$ & $1.2(0.33)$ & & \\
\hline
\end{tabular}

Anemone caroliniana (Ranunculaceae), Oenothera speciosa (Onagraceae) (plant key used is Diggs et al. 1999).

Because Solidago increased in abundance during the experimental period compared to other species, data were also analysed with actual species evenness as an independent regression variable (Table 1 , Fig. 1). Results were consistent with the analyses based on planted species evenness. The number of dicot seedlings significantly declined with actual species evenness of plots during 2000 (Fig. 1) (1999, $P=0.16$, 2000: March $P<0.05$, May $P<0.05$, June $P<0.01$, October $P<0.01)$, and there were no significant differences among species identity groups nor interactions between evenness and species identity.

There was no affect of species evenness or identity on seedling numbers of seeded Monarda citriodora during 2000 (Table 1). (Because there were relatively few seedlings during some dates, and there were some zeroes in the data set, sampling dates were combined). There were trends for grass seedling abundance to be negatively related to the evenness of the plots, and this trend was close to being significant only for the October 2000 sampling period (planted, $P=0.06$, actual $P=0.04$, slope -4.5 ). However, the main effect of evenness and the time by evenness interaction were not significant. Common invasive grass seedlings were Bromus japonicus, Hordeum pusillum and Limnodea arkansana.

\section{Spittle bugs}

The proportion of Solidago stems containing spittle masses (a measure of infestation rate) was inversely related to species evenness (Table 1, Fig. 2). Spittle bug infestation rate also varied depending on which species dominated the plot: with highest infestation rates on Solidago in Bothriochloa ischaemum - and Bothriochloa laguroides-dominated plots. There was no significant interaction between evenness and species identity of the dominant, but there was a slight tendency for the relationship with evenness to be stronger in plots dominated by Bothriochloa ischaemum and Sporobolus than in plots dominated by the other two species. There was no difference in the absolute number of stems infested among evenness treatments (evenness main effect: $P=0.55$ ). Spittle bug infestation frequency declined with the density of Solidago shoots when all plots were combined $(r=-0.48$, $P<0.01)$.

\section{Environmental variables}

Soil percentage water content to $15 \mathrm{~cm}$ did not vary among treatments during 2000 (planted: time $F=190.6$, $P<0.001$, all other factors, $F<2.0, P>0.30$; actual: time $F=13.2, P<0.001$, all other factors, $F<2.0, P>0.27$ ). Soil water averaged (mean) $13.7 \%$ with a SE of $0.8 \%$ and a CV of 6.0.

Light penetration to the soil surface during 2000 was species-specific and did not explain seedling invasion patterns. When data were analysed with planted levels of evenness, there were no significant differences among treatments (species and evenness main effects, $P>0.05$, species-evenness interaction, $P=0.12$ ). When light penetration data were analysed using actual species evenness, significant differences were found among dominant species groups $(P<0.05)$, and the identity of the dominants significantly influenced the evenness effects (species- 

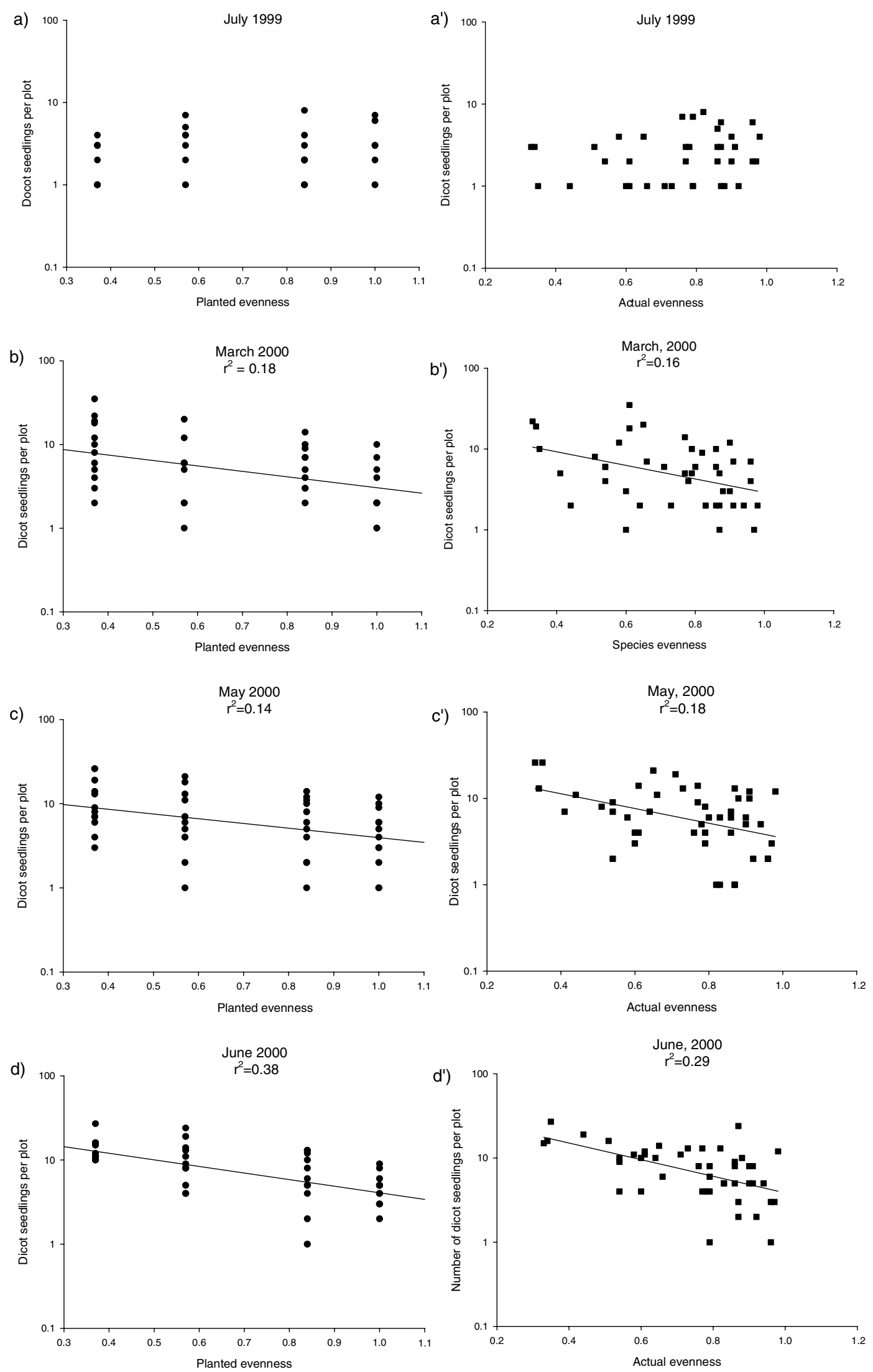

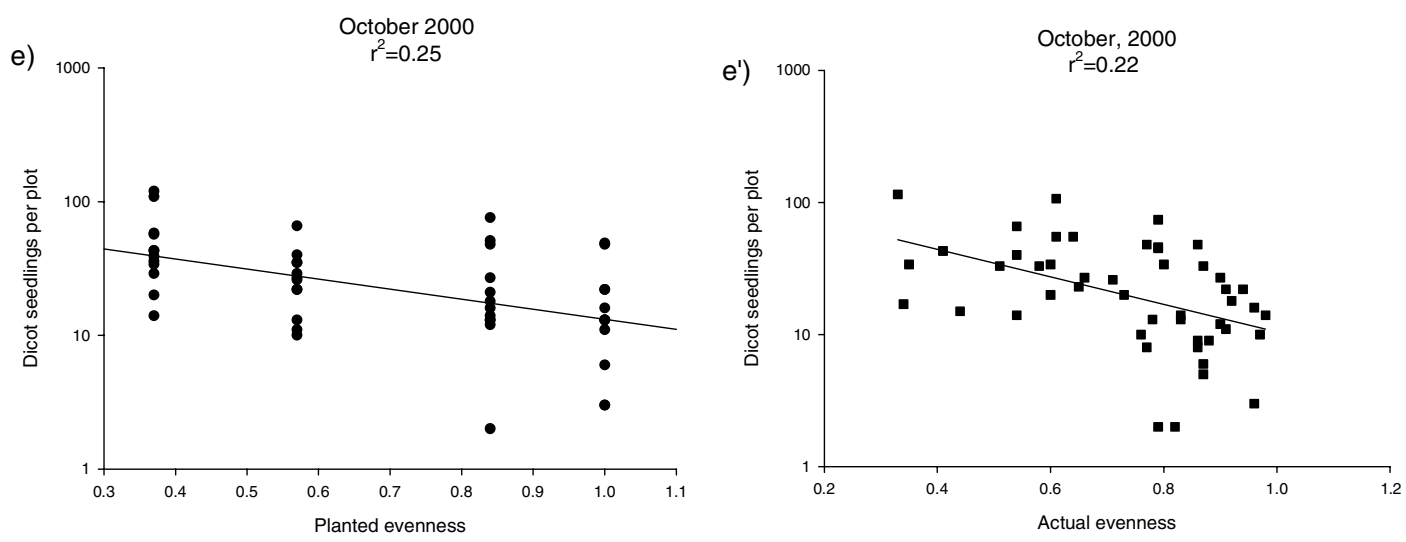

Figure 1 Number of dicot invaders in experimental plots during July 1999, March 2000, May 2000, June 2000 and October 2000 as a function of planted (a-e, $n=12$ per group) and actual $\left(\mathrm{a}^{\prime}-\mathrm{e}^{\prime}, n=48\right)$ species evenness (Simpson's E).

Frequency of spittle bugs on Solidago canadensis 1999

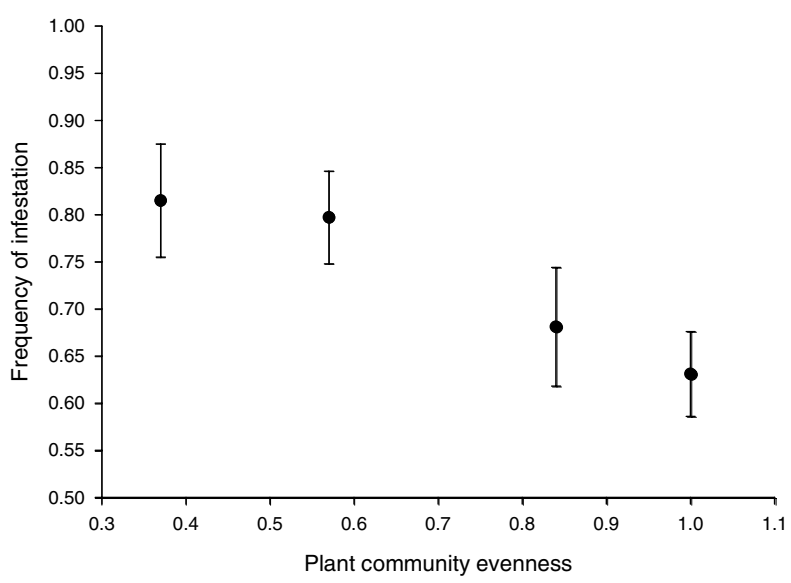

Figure 2 Proportion of Solidago stems that had spittle masses from the spittle bug Clastoptera xanthocephala in experimental plots ( $n=12$ per group, $r^{2}=0.17$, linear contrast $P=0.01$ ).

evenness interaction, $P<0.04)$. Light penetration increased with declining species evenness if Sporobolus asper was dominant ( $b=0.79, P<0.03$ ), but decreased if $B$. ischaemum was dominant $(b=-0.65, P<0.03)$. There were no relationships between light penetration and species evenness when the other two species were dominant (Solidago canadensis, $P=0.19$, B. laguroides, $P=0.95)$.

\section{DISCUSSION}

In this study, we tested the hypothesis that low diversity plant communities are more invasible by weeds and an important sap-sucking insect than are high diversity plant communities by varying species evenness. Earlier experimental tests of this hypothesis varied richness. In these tests, negative effects of diversity on plant invasibility were interpreted to result either because high richness communities utilized a greater proportion of resources that left fewer available for invaders (e.g. Knops et al. 1999; Naeem et al. 2000) or as being caused by the sampling effect, i.e. high richness plots were more likely to contain aggressive species that were harder to invade (Wardle 2001). By varying evenness and keeping species richness constant, the diversity hypothesis could be tested without including the sampling effect, because the same species were present in all plots (Wilsey \& Potvin 2000). For example, our evenness treatments produced diversity values of $4,3.4,2.3$, and 1.5, when a diversity index (Simpson's D) was calculated that included both richness and evenness components. We utilized only four species, rather than a higher number, because these grasslands (as do many plant communities) have relatively few abundant species (Grime 1998).

We found significantly reduced total dicot numbers with increasing species evenness of our plots, whether data were analysed with the original planting treatments as a categorical variable or with the actual (measured) levels of evenness. This suggests that invasion success increased (for dicots in general) with reductions in species diversity. However, the numbers of experimentally seeded Monarda citriodora did not vary among treatments. Most experimental tests of effects of plant community diversity on invasion success use a single invader species as their test species (e.g. Knops et al. 1999; Naeem et al. 2000; Lyons \& Schwartz 2001). If we had used only Monarda to test for invasibility, we would have incorrectly concluded that evenness had no effect on invasion success. The total number of invaders of all species is a better (more general) test of invasibility because invader species are replicated and thus results are not influenced by idiosyncratic behaviour of a single species. Based on these results, we suggest that studies that include the entire pool of invading species rather than a single 'target' species will 
provide greater generality to a variety of ecosystems and species.

In contrast to dicot invaders, which invaded continuously for much of the growing season, the grass invaders tended to invade in pulses during periods of semi-dormancy in experimental plants (i.e. at the beginning of the growing season and just before the autumn rains). At these times, there was a weaker relationship found between evenness and grass invader numbers. The different responses between dicot and grass invaders could have been caused by this pulse vs. continuous type of invasion, by some functional difference between grasses and dicots, or because of reduced statistical power in the grass analyses.

Although reduced species evenness increased invasibility of dicots, the resources that caused this increase remain unidentified. Soil water to $15 \mathrm{~cm}$ and light availability at the soil surface were not significantly different among dominant species or evenness treatments. Although mean water and light availability remained unaffected by treatments, it could be that there were micropatch locations within some plots that had high availability of light and water or of other (unmeasured) resources, and that these were the areas where dicots easily invaded. If these locations were counterbalanced with other micropatches that had low light and water, then the mean for plots would remain unchanged. In a similar vein, Kennedy et al. (2002) found that invaded neighbourhoods in Minnesota grasslands were less dense, less species-rich, and less 'crowded' than neighbourhoods within the same plot that were not invaded. Further research should be done on both the mean and patchiness of limiting resources, and on neighbourhood effects on these resources to determine what causes high evenness plots to be less invasible than low evenness plots.

In the growing body of species richness/ecosystem functioning literature, there has been relatively little emphasis on higher trophic levels (e.g. Naeem et al. 1994; Naeem \& Li 1998; Van der Heijden et al. 1998; Mulder et al. 1999; Koricheva et al. 2000; Norberg 2000). Van der Heijden et al. (1998) and Mulder et al. (1999) found that the lack of mychorrizal fungi and insect feeding dampened productivity/richness relationships. Root's Resource Concentration Hypothesis (Root 1973) predicts that plants in low diversity communities should have a greater herbivore load than plants in high diversity communities. In support of this, we found that a decrease in plant species evenness led to an increased frequency of infestation of Solidago by the spittle bug Clastoptera xanthocephala. However, the mechanism was different than predicted and depended more on a simple dilution effect because the absolute number of spittle masses per plot did not vary among evenness treatments. What did vary was the frequency of infestation, i.e. the same number of spittle masses were diluted in high evenness plots that had more Solidago stems. In low evenness plots, the spittle masses were concentrated on the fewer Solidago stems.

Spittle bugs are sometimes very abundant in old fields, presumably because their spittle acts as an affective antipredator agent (Whittaker 1970; Root \& Cappuccino 1992). Spittle bugs were found to have a significant negative impact on Solidago growth and reproductive rate by Meyer (1993) and Carson \& Root (1999). Meyer (1993) experimentally varied xylem feeding (spittle bug), phloem feeding, and leaf chewing insect densities on Solidago and found that spittle bugs had a 5-6 times greater negative impact on Solidago than did other feeding types. Carson \& Root (1999) sprayed plots with insecticide (to reduce spittle bug abundance) and found that Solidago abundance increased and plant species richness decreased in New York old fields. Bazzaz (1996) found that high dominance of Solidago is associated with a reduction in plant diversity in midwestern USA old fields. Although spittle bugs were present in our study for a very short time period, and apparently did not affect stem density, our results indicate that spittle bugs were more concentrated on Solidago in low evenness stands that had fewer Solidago stems. If our result turns out to be general, then the detrimental affect that spittle bugs have on Solidago may be greater when community evenness is low, or when abundance of Solidago is low for other reasons. Thus, management regimes that decrease community evenness by increasing the dominance of grasses (decreasing Solidago abundance) may increase the effectiveness with which spittle bugs limit Solidago. Lower abundance of grasses and/or greater abundance of Solidago should make spittle bugs less effective as control agents.

Previous field experiments that have varied species richness (e.g. Hector et al. 1999; Tilman et al. 2001) have used seed mixes with higher species evenness than what would normally occur in natural communities (Huston 1997; Doak et al. 1998; Grime 1998; Schwartz et al. 2000), although evenness probably declines somewhat below seeded evenness as species rank abundance relationships are developed. Our results suggest that invasion rates may be somewhat underestimated in these plots compared with more realistic (lower) evenness levels. However, whether low evenness constrains relationships between invasion rates and species richness (Doak et al. 1998; Schwartz et al. 2000), which is a more important issue, remains to be experimentally tested.

In summary, we varied plant species diversity by varying evenness, which varied diversity without the sampling effect, because all plant species were found in all the plots. We found that a reduction in plant species evenness led to an increase in the number of dicot herbs. This trend was not found for a target dicot species Monarda citriodora, and was only found when all invading dicot species were considered. The resources that caused this effect remain unidentified. 
We also found that a reduction in species evenness led to an increase in the frequency of spittle bugs on Solidago. In contrast to plant invader success (primary producer trophic level), however, the spittle bug effect (consumer trophic level) was apparently caused by a simple dilution effect.

\section{ACKNOWLEDGEMENTS}

We thank Chris Kolodziejczyk and Katherine Jones for help in planting and sampling the plots. Three anonymous referees made some useful comments on an earlier version of this manuscript. This work was partially funded by USDA-ARS Specific Cooperative agreement no. 58-6206-0023.

\section{REFERENCES}

Aarssen, L.W. (1997). High productivity in grassland ecosystems: effected by species diversity or productive species? Oikos, 80 , 183-184.

Bach, C.E. (1980). Effects of plant density and diversity on the population dynamics of a specialist herbivore, the striped cucumber beetle, Acalymma vittata (Fab). Ecology, 61, 15151530.

Bazzaz, F.A. (1996). Plants in Changing Environments. Cambridge University Press, Cambridge, UK.

Burke, M.J.W. \& Grime, J.P. (1996). An experimental study of plant community invasibility. Ecology, 77, 776-791.

Carson, W.P. \& Root, R.B. (1999). Top-down effects of insect herbivores during early succession: influences on biomass and plant dominance. Oecologia, 121, 260-272.

Chapin, F.S., Walker, B.H., Hobbs, R.J., Hooper, D.U., Lawton, J.H., Sala, D.E. \& Tilman, D. (1997). Biotic control over the functioning of ecosystems. Science, 277, 500-504.

Davis, M.A., Grime, J.P. \& Thompson, K. (2000). Fluctuating resources in plant communities: a general theory of invasibility. J. Ecol., 88, 528-534.

Diggs, G.M., Lipscomb, B.L. \& O’Kennon, R.J. (1999). Shinner's and Mabler's Illustrated Flora of North Central Texas. Botanical Research Institute of Texas, Fort Worth, USA.

Doak, D.F., Bigger, D., Harding, E.K., Marvier, M.A., O’Malley, R.E. \& Thompson, D. (1998). The statistical inevitability of stability-diversity relationships in community ecology. Am. Naturalist, 151, 264-276.

Elton, C.S. (1958). The Ecology of Invasions by Animals and Plants. Methuen, London.

Grime, J.P. (1998). Benefits of plant diversity to ecosystems: immediate, filter and founder effects. J. Ecol., 86, 902-910.

Hector, A., Schmid, B., Beierkuhnlein, C., Caldeira, M.C., Diemer, M., Dimitrakopoulos, P.G. et al. (1999). Plant diversity and productivity experiments in European grasslands. Science, 286, 1123-1127.

Howe, H.F. \& Westley, L.C. (1988). Ecological Relationships of Plants and Animals. Oxford University Press.

Huenneke, L.F., Hamburg, S.P., Koide, R., Mooney, H.A. \& Vitousek, P. (1990). Effects of soil resources on plant invasion and community structure in California serpentine grassland. Ecology, 71, 478-491.
Huston, M.A. (1997). Hidden treatments in ecological experiments: re-evaluating the ecosystem function of biodiversity. Oecologia, 110, 449-460.

Kennedy, T.A., Naeem, S., Howe, K.M., Knops, J.M.H., Tilman, D. \& Reich, P. (2002). Biodiversity as a barrier to ecological invasion. Nature, 417, 636-638.

Knops, J.M.H., Tilman, D. \& Haddad, N.M. (1999). Effects of plant species richness on invasion dynamics, disease outbreaks, insect abundances and diversity. Ecol. Lett., 2, 26-293.

Koricheva, J., Mulder, C.P.H., Schmid, B., Joshi, J. \& Huss-Danell, K. (2000). Numerical responses of different trophic groups of invertebrates to manipulations of plant diversity in grasslands. Oecologia, 125, 271-282.

Levine, J.M. (2000). Species diversity and biological invasions: relating local process to community pattern. Science, 288, 852-854.

Levine, J.M. \& D’Antonio, C.M. (1999). Elton revisited: a review of evidence linking diversity and invasibility. Oikos, 87, 15-26.

Lord, L.A. \& Lee, T.D. (2001). Interactions of local and regional processes: species richness in tussock sedge communities. Ecology, 82, 313-318.

Lyons, K.G. \& Schwartz, M.W. (2001). Rare species loss alters ecosystem function - invasion resistance. Ecol. Lett., 4, 358-365.

MacArthur, R.H. (1972). Species-packing and competitive equilibrium for many species. Theor. Popul. Biol., 1, 1-11.

Meyer, G.A. (1993). A comparison of the impacts of leaf- and sapfeeding insects on growth and allocation of goldenrod. Ecology, 74, 1101-1116.

Mulder, C.P.H., Koricheva, J., Huss-Danell, K., Högberg, P. \& Joshi, J. (1999). Insects affect relationships between plant species richness and ecosystem processes. Ecol. Lett., 2, 237-246.

Naeem, S., Knops, J.M.H., Tilman, D., Howe, K.M., Kennedy, T. \& Gale, S. (2000). Plant diversity increases resistance to invasion in the absence of covarying extrinsic factors. Oikos, 91, 97-108.

Naeem, S. \& Li, S. (1998). Consumer species richness and autotrophic biomass. Ecology, 79, 2603-2615.

Naeem, S., Thompson, L.J., Lawler, S.P., Lawton, J.H. \& Woodfin, R.M. (1994). Declining biodiversity can alter the performance of ecosystems. Nature, 368, 734-736.

Nijs, I. \& Roy, J. (2000). How important are species richness, species evenness and interspecific differences to productivity? A mathematical model. Oikos, 88, 57-67.

Norberg, J. (2000). Resource-niche complementarity and autotrophic compensation determines ecosystem-level responses to increased cladoceran species richness. Oecologia, 122, 264-272.

Prieur-Richard, A.H., Lavorel, S., Grigulis, K. \& Dos Santos, A. (2000). Plant community dynamics and invasion by exotics: invasion of Mediterranean old fields by Consya bonariensis and Consya canadensis. Ecol. Lett., 2, 412-422.

Robinson, G.R., Quinn, J.F. \& Stanton, M.L. (1995). Invasibility of experimental habitat islands in a California winter annual grassland. Ecology, 76, 786-794.

Root, R.B. (1973). Organization of a plant-arthropod association in simple and diverse habitats: the fauna of collards (Brassica oleracea). Ecol. Monographs, 43, 95-124.

Root, R.B. \& Cappuccino, N. (1992). Patterns of population change and the reorganization of the insect community associated with goldenrod, Solidago altissima. Ecol. Monogr., 62, 393-420.

Schwartz, M.W., Brigham, C.A., Hoeksema, J.D., Lyons, K.G., Mills, M.H. \& Van Mantgem, P.J. (2000). Linking biodiversity to 
ecosystem function: implications for conservation ecology. Oecologia, 122, 297-305.

Smith, M.D. \& Knapp, A.K. (1999). Exotic plant species in a $\mathrm{C}_{4^{-}}$ dominated grassland: invasibility, disturbance, and community structure. Oecologia, 120, 605-612.

Stirling, G. \& Wilsey, B. (2001). Empirical relationships between species richness, evenness, and proportional diversity. Am. Naturalist, 158, 286-299.

Stohlgren, T.J.D., Binkley, G.W., Chong, M.A., Kalkhan, L.D., Schell, K.A., Bull., Y. et al. (1999). Exotic plant species invade hot spots of native plant diversity. Ecol. Monographs, 69, 25-46.

Tilman, D., Lehman, C.L. \& Thomson, K.T. (1997). Plant diversity and ecosystem productivity: theoretical considerations. Proc. Natl. Acad. Sci., 94, 1857-1861.

Tilman, D., Reich, P.B., Knops, Wedin, J., Mielke, D., T. \& Lehman, C. (2001). Diversity and productivity in a long-term grassland experiment. Science, 294, 843-845.

Tilman, D. Wedin, D. \& Knops, J. (1996). Productivity and sustainability influenced by biodiversity in grassland ecosystems. Nature, 379, 718-720.

Van der Heijden, M.G.A. Klironomos, J.N. Ursk, M. Uoutoglis, P. Streztwolf-Engel, R. Botter, T. et al. (1998). Mycorhizal fungal diversity determines plant biodiversity, ecosystem variability and productivity. Nature, 396, 69-72.

Wardle, D.A. (2001). Experimental demonstration that plant diversity reduces invasibility - evidence of a biological mechanism or a consequence of sampling effect? Oikos, 95, 161-170.

Whittaker, J.B. (1970). Cercopid spittle as a microhabitat. Oikos, 21, 59-64.

Wilcove, D.S., Rothstein, D., Dubow, J., Phillips, A. \& Losos, E. (1998). Quantifying threats to imperilled species in the United States. Bioscience, 48, 607-615.

Wilsey, B.J. \& Potvin, C. (2000). Biodiversity and ecosystem functioning: importance of species evenness in an old field. Ecology, 81, 887-892.

Editor, D. Wardle

Manuscript received 5 June 2002

First decision made 4 July 2002

Manuscript accepted 19 July 2002 